\title{
PREFERENCE AND AREA COORDINATION OF PUBLIC TRANSPORT IN MODERN CITY
}

\author{
Ivana Hurtova ${ }^{1}$, Marie Sejkorova ${ }^{1}$, Jan Verner ${ }^{1}$, Michal Kucera ${ }^{2}$ \\ ${ }^{1}$ University of Pardubice, Czech Republic; ${ }^{2}$ University of Defence, Czech Republic \\ ivana.hurtova@upce.cz,marie.sejkorova@upce.cz,jan.verner@upce.cz, michal.kucera@unob.cz
}

\begin{abstract}
The purpose of the document is to analyse and evaluate the situation in the field of chronometrations of the town's public transport company Dopravní společnost Zlín-Otrokovice (DSZO) in the Czech Republic in relation to the project "Preference and Area Coordination of Public Transport" and to carry out an evaluation in the sense of evaluation of time savings. In this paper methodological procedures are used corresponding to the procedures, which have been used in the past years with the aim of maximizing transparency and comparability of data and outputs. The project "Preference and Area Coordination of Public Transport" in the town's public transport company Zlín-Otrokovice is connected with 39 junctions with traffic light. Measures to build an active preference system had a significant effect on the main tracking parameter, i.e. the driving time of public transport vehicles. The computational algorithm for the monitored parameter is given by calculating the time savings in public transport. The rate of improvement of the driving time of public transport vehicles in 2017 will be determined compared to the original condition in 2009. In 2017 it had a company DSZO with 53 trolleybuses and 37 buses. The total distance of all 21 lines in both directions is 384,669 meters. The aim of the analysis is to evaluate, how the system of active preference was reflected in the reduction of driving times on public transport vehicle lines. As will be apparent from the results presented in this document, it can be stated that the time savings on the public transport DSZO lines have been achieved.
\end{abstract}

Keywords: preference, traffic control centre, public transport, shorter travel times.

\section{Introduction}

Car travel is related to climate change, dependence on fossil fuels, and traffic congestion. Reducing the share of trips made by car might help combat oil dependence, global warming, and environmental pollution. Germany and the USA have among the highest motorization rates in the world. Yet Germans make a four times higher share of trips by foot, bike, and public transport and drive for a $25 \%$ lower share of trips as Americans [1].

In order to satisfy the need to move, public transport has become the most frequently used mode of transport in recent times. Therefore, the way public transport services are delivered and also their qualities are important because of their impact on the attitude as well as on the behaviour of travellers and the demand for services [2].

Safety is the need for comfort which is conceptualised to include; ease convenience and contentment of the mode of transport. The final need/factor is the pleasurability, which is a higher derivative of comfort and seen as a form of enjoyment of the trip based on the mode of travel. Psychographic variables include variables such as affordability, accessibility, availability of mode options, length of waiting time, safety/security of mode, comfort/convenience, reliability of modes and many others [3].

One of the possibilities of increasing the attractiveness and competitiveness of public transport vehicles in the urban agglomeration is the application of modern traffic control elements ensuring the active preference of public transport.

Another suitable solution of ensuring the preference for public transport vehicles is building selected lanes for public transport vehicles. In this way, the public transport vehicles would be segregated from other road users and thus the delays would be avoided and the traffic flow continuity would be increased. However, this solution is possible only on communications, which have sufficient space conditions. Drivers will be informed about selected lanes by traffic signs (variable message signs or road markings) [4].

Establishing a reasonable connecting preference is one of the most important opinions to give priority to the development of urban public transport now [5]. Extremely busy main roads, uncomfortable waiting in traffic columns at overcrowded traffic junctions in the city centre, or traffic jams are unpleasant not only for the drivers. This situation has a very negative impact on urban public transport services, which have numerous delays in transport and thus reduce the quality of their 
services. The situation is also complicated by the fact that the electronic control of the network of traffic lights is quite inadequate for public transport.

The ambition of the "Preference and Area Coordination of Public Transport" project in the town's public transport company DSZO is to minimize the impacts of the negative impacts on public transport services through preferential measures at traffic lights in favor of public transport. An essential prerequisite for the full functioning of this preference is the overall optimization of traffic management for all its components, not only for public transport.

The article focuses on introducing a project, in which a system of traffic-dependent coordinated dynamic control of traffic lights with active preference of public transport vehicles in the town's public transport company DSZO on the routes of all public transport lines was built. Systemic coordination of the follow-up traffic lights will ensure the smooth flow of public transport vehicles, taking into account the time of stay at stops. This is the so-called "green wave".

As stated by the author [6], shortening of driving times is reflected in saving time for all passengers in all the connections that pass through the section. This relationship can be used to calculate the total financial savings for a given segment at an increased number of passengers and increased rush hour.

\section{Materials and methods}

In order to develop preference DSZO created the idea of a preferential measure aimed at defining contiguous sections with a high proportion of preference in sections with intensive public transport, where the positive effects of the implemented measures would be the highest. Based on the decisionmaking process a SWOT analysis was made (Table 1).

It was necessary to specify the objectives of the project and identify the internal and external factors that are favourable and unfavourable to achieving those objectives. Strengths include the acceleration and fluidity of public transport vehicles and the associated reduction of negative environmental impacts. Building an active preference usually leads to high acquisition costs. Reducing operating costs and reducing vehicle counts is an opportunity for management DSZO.

Table 1

SWOT analysis for the active preference decision process

\begin{tabular}{|c|c|}
\hline Strengths & Weaknesses \\
\hline the process of public transport speeded up & high acquisition costs \\
\hline $\begin{array}{l}\text { minimizing time losses of public transport } \\
\text { vehicles }\end{array}$ & limiting automotive traffic \\
\hline $\begin{array}{l}\text { limiting the number of vehicles on the lines of } \\
\text { energy savings achieved by reducing the } \\
\text { number of brakes and starts }\end{array}$ & limit space options \\
\hline $\begin{array}{l}\text { reducing all the negative effects of transport } \\
\text { on the environment }\end{array}$ & requirements for lightning control systems \\
\hline $\begin{array}{c}\text { Opportunities } \\
\end{array}$ & $\begin{array}{c}\text { Threats } \\
\end{array}$ \\
\hline efficient use of the transport area & $\begin{array}{l}\text { worsening of the throughput of nearby } \\
\text { intersections }\end{array}$ \\
\hline reducing operating costs & high acquisition costs \\
\hline $\begin{array}{l}\text { minimizing time losses of public transport } \\
\text { vehicles }\end{array}$ & $\begin{array}{l}\text { transferring congestion to other locations, } \\
\text { including the risk of disruption of public transport } \\
\text { at these locations }\end{array}$ \\
\hline $\begin{array}{l}\text { acceleration of average vehicle speeds on } \\
\text { lines }\end{array}$ & \\
\hline $\begin{array}{l}\text { reducing the number of vehicles on the lines } \\
\text { without degrading the operating parameters }\end{array}$ & \\
\hline increasing prestige of public transport & \\
\hline
\end{tabular}


Basic equipment includes a controller, a detector, an outfit. A detailed description of the technology of preference is given by the author in his dissertation thesis [7]. Active preference is not allocated to public transport vehicles absolutely; the system always evaluates the current situation and decides on the allocation of a preferential measure or its non-allocation.

For this reason it was necessary to implement the following measures in Zlín and Otrokovice:

- Modification of 38 traffic light controllers in the target agglomeration.

- Linking most controllers to coordinated moves.

- Establishment of a new traffic control centre, which will ensure the supervision and monitoring of all connected traffic lights via transmission routes, with the possibility of collecting traffic and traffic data for continuous optimization of traffic-dependent signalling plans and optimization of preferential conditions and situations.

- Complete system programming.

The carrier has equipped its public transport vehicles with new on board computers and radio modems, i.e. devices that communicate with individual system preference points.

The secondary effect of the project is the overall optimization of the transport network, which is necessary to achieve high system efficiency. The other users of the transport network in the city also benefit from the project.

The public urban transport preference presents the provision of the right of way to public transport vehicles at signal controlled junctions and most fluency passage of vehicles through the junction is ensured and time losses connected with waiting on junction are minimized [8].

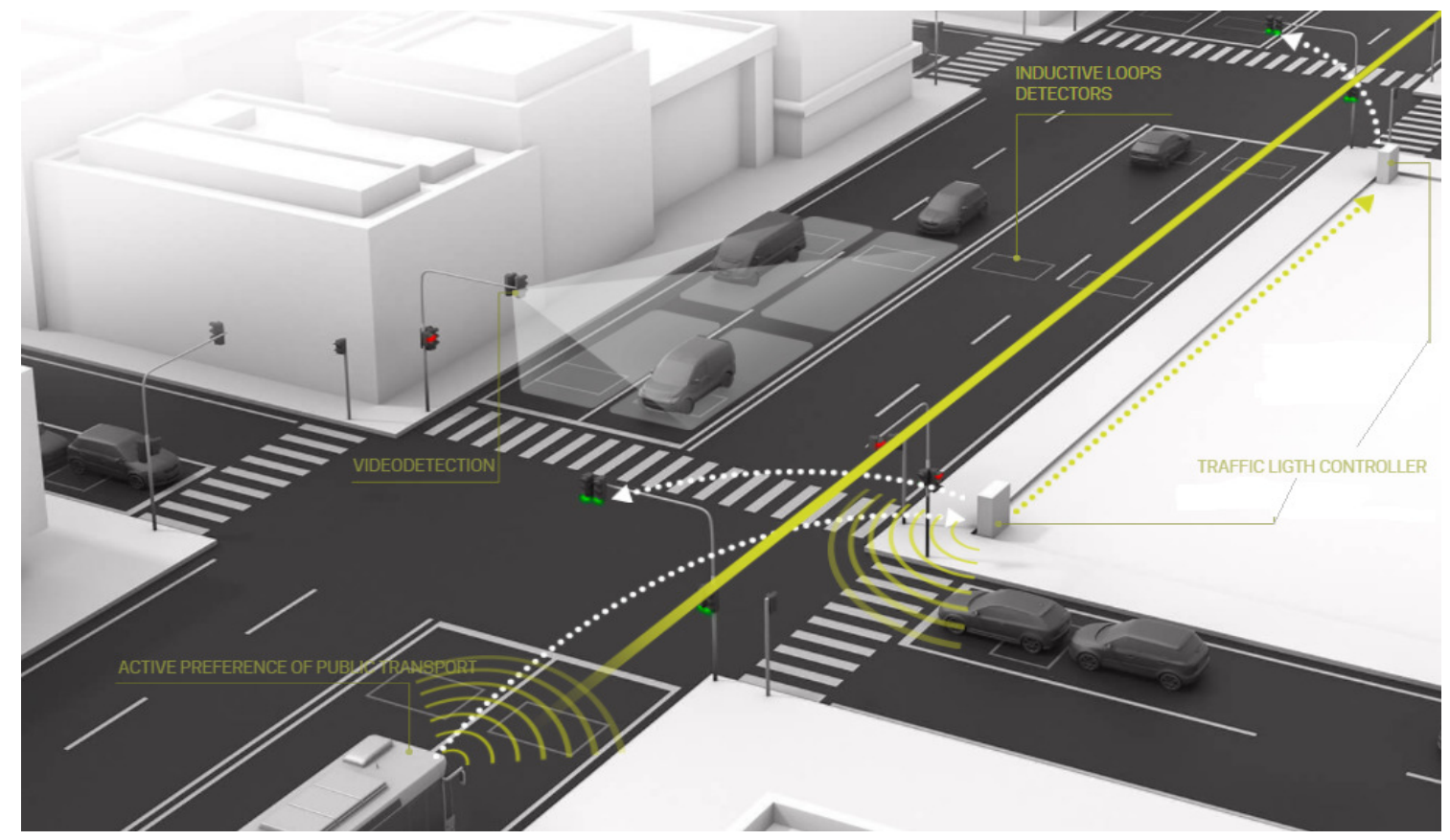

Fig. 1. System active preference of public transport [9]

The active preference system used for public transport vehicles in Zlín and Otrokovice is shown in Figure 1. The urban transport vehicle is approaching a junction with green signal in the direction of travel; the vehicle uses a radio modem to $\log$ in to the intersection controller. Based on the vehicle's position Global Positioning System (GPS) and driving speed, the system calculates that, without changing the intersection signal cycle, the urban traffic vehicle will have to stop at the junction (this is an undesirable state); the system, for example, calculates that if the green signal lengthens for another 3 seconds, the urban transport vehicle will still be able to drive without stopping; On the basis of the calculation, the system adjusts the current intersection signal cycle, and the urban transport vehicle actually goes without stopping; the system will then modify the signal cycles of the other junctions that are involved with the intersection with this intersection and will not break the green wave for the other traffic. 
The system uses two-way online communication that informs a traffic controller about the current position of an incoming vehicle or a vehicle stopped at a nearby bus stop. The controller utilises this information for an optimisation of control and adapts (extends) green time in the direction of the vehicle passage. At the same time, the vehicle driver is informed about the optimum time for quick and uninterrupted passage through the intersection [9].

The output of the project was to build an infrastructure for the preference of public transport in Zlín and Otrokovice at the intersections controlled by the traffic lights and the system of preference of public transport with the components placed in the public transport vehicles company Dopravní společnost Zlín-Otrokovice. Figure 2 shows a complete network of the town's public transport company Dopravní společnost Zlín-Otrokovice with a total distance of 384,669 meters and marked lines.

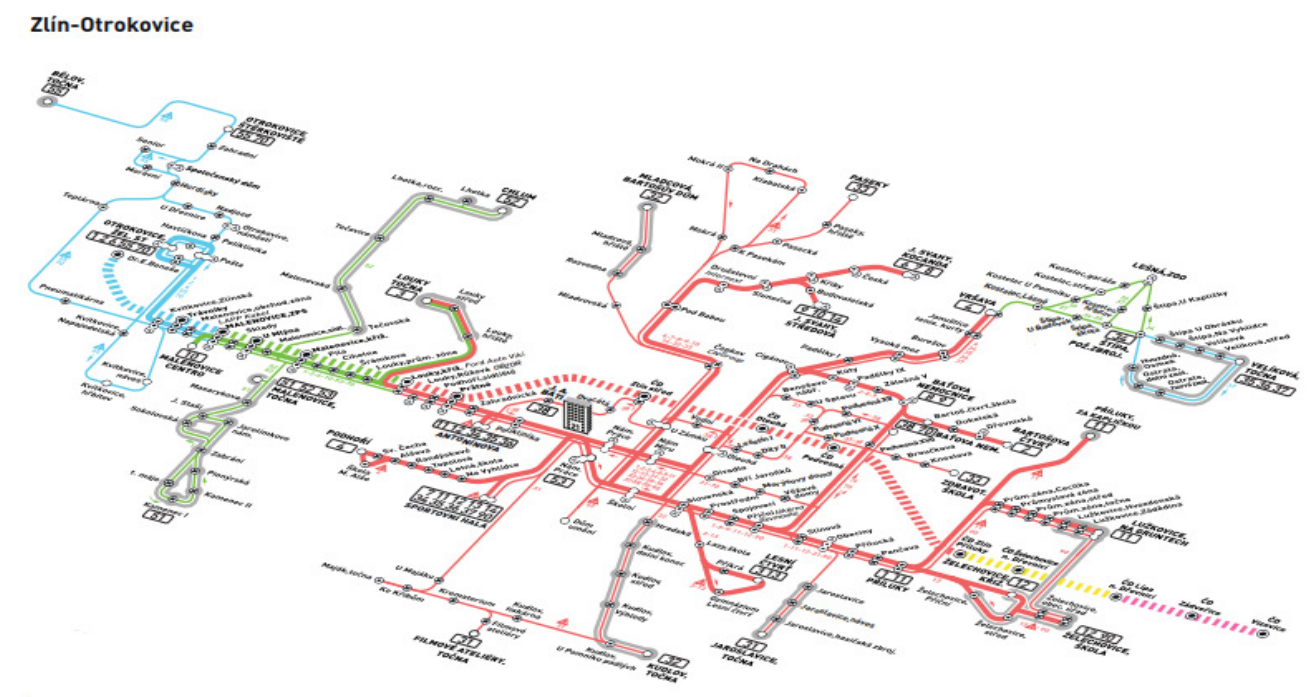

Fig. 2. Map of complete network of urban transport lines in Zlín and Otrokovice.

\section{Results and discussion}

In order to ensure comparability of pre-preference calculations with the control calculations processed for this document, a check of the status of individual lines was required prior to the start of the analysis. It was necessary to have comparable data and filter out the influence of factors such as significant line changes due to road repairs, changes in line trace lengths, new stops during the route.

Circulation time is defined as the sum of travel times in both directions of the line, breaks at both finite and handling times (1):

$$
t_{\text {circ }}=t_{\text {run }}+t_{\text {man }}+t_{\text {paus }}
$$

where $t_{\text {circ }}-$ circulation time of a given line, $\mathrm{s}$;

$t_{\text {run }}$ - run time in either direction, s;

$t_{\text {man }}$ - vehicle manipulation time on final, s;

$t_{\text {paus }}$ - pause time on the final, s;

When preferential arrangements were introduced, the travel time was changed. Thanks to this, the entire running time can be shortened (2):

$$
t_{\text {circ.pref }}=\left(t_{\text {run }}-t_{\text {pref }}\right)+t_{\text {man }}+t_{\text {paus }}
$$

where $t_{\text {circ.pref }}-$ line circulation time after the introduction of preferential arrangements, $\mathrm{s}$; $t_{\text {.pref }}-$ reducing driving time before preference, $\mathrm{s}$;

The possibilities for shortening travel time are proportional to the responses of the system, to which shorter travel times are to be implemented, the intensity of involvement of preferential measures (degree of preference) and the existence of external influences affecting the traffic situation. Table 2 gives a detailed quantification of time savings on individual urban transport lines before and after active preferences are introduced. There is a clear time saving on each public transport line. 
The computational algorithm is based on the calculation of time savings in public transport. Determining the improvement rate over the original state is given by (3):

$$
\left(n_{2009}-n_{2017}\right) / n_{2009}
$$

where $n$-driving time expressed per line, s;

2009 - year of operation of public transport without preference

2017 - year of traffic operation with active preference

The calculation of time savings on individual lines in seconds in 2017 is summarized in the table below. It is clear from the table that, compared to 2009, when urban transport traffic was without active preference, there were positive changes.

Total time savings on the town's public transport company Dopravní společnost Zlín-Otrokovice lines have been affected by the build-up of an active preference system. The distance of public transport lines counted in both directions is 384,669 meters. This distance was travelled in 2009, when the preference was not active, in 65,520 seconds. In 2017, when active preferences were introduced, the same distance was travelled in 59,940 seconds. The difference between these parameters - the driving time of urban transport vehicles in 2009 and 2017, shows the time savings on all public transport lines in seconds and as a percentage. These time savings reached 5,580 seconds and $8.5 \%$.

Table 2

Quantification of time saving on individual routes in minutes before and after introducing active preference of public transport

\begin{tabular}{|c|c|c|c|c|c|}
\hline \multirow{3}{*}{ Route } & \multirow{3}{*}{ Distance, m } & \multirow{2}{*}{\multicolumn{2}{|c|}{$\begin{array}{c}\text { Travel time, } \mathbf{s} \\
\text { Preference } \\
\end{array}$}} & \multirow{2}{*}{\multicolumn{2}{|c|}{ Difference }} \\
\hline & & & & & \\
\hline & & Without (2009) & With (2017) & $\mathbf{s}$ & $\%$ \\
\hline 1 & 28,976 & 4,680 & 4,260 & 420 & $9.0 \%$ \\
\hline 2 & 29,333 & 5,040 & 4,620 & 420 & $8.3 \%$ \\
\hline 3 & 13,668 & 2,580 & 2,340 & 240 & $9.3 \%$ \\
\hline 4 & 12,831 & 2,640 & 2,520 & 120 & $4.5 \%$ \\
\hline 6 & 28,978 & 4,740 & 4,260 & 480 & $10.1 \%$ \\
\hline 8 & 13,994 & 2,760 & 2,580 & 180 & $6.5 \%$ \\
\hline 9 & 12,391 & 2,460 & 2,220 & 240 & $9.8 \%$ \\
\hline 10 & 21,397 & 3,660 & 3,240 & 420 & $11.5 \%$ \\
\hline 11 & 15,526 & 2,760 & 2,520 & 240 & $8.7 \%$ \\
\hline 12 & 15,101 & 2,640 & 2,400 & 240 & $9.1 \%$ \\
\hline 13 & 6,217 & 1,440 & 1,260 & 180 & $12.5 \%$ \\
\hline 14 & 8,282 & 1,800 & 1,620 & 180 & $10.0 \%$ \\
\hline 31 & 19,455 & 3,240 & 2,880 & 360 & $11.1 \%$ \\
\hline 32 & 15,734 & 2,280 & 2,160 & 120 & $5.3 \%$ \\
\hline 33 & 16,949 & 3,360 & 3,120 & 240 & $7.1 \%$ \\
\hline 34 & 17,785 & 2,640 & 2,520 & 120 & $4.5 \%$ \\
\hline 35 & 24,506 & 3,300 & 3,060 & 240 & $7.3 \%$ \\
\hline 36 & 28,649 & 4,020 & 3,780 & 240 & $6.0 \%$ \\
\hline 53 & 11,986 & 2,220 & 2,040 & 180 & $8.1 \%$ \\
\hline 55 & 12,437 & 2,280 & 2,100 & 180 & $7.9 \%$ \\
\hline 70 & 30,474 & 4,980 & 4,440 & 540 & $10.8 \%$ \\
\hline \multicolumn{5}{|c|}{ Total pre-preference time, $\mathrm{s}$} & 65,520 \\
\hline \multicolumn{5}{|c|}{ Total preference time, $\mathrm{s}$} & 59,940 \\
\hline \multicolumn{5}{|c|}{ Number of seconds saved, $\mathrm{s}$} & 5,580 \\
\hline
\end{tabular}




\section{Fleet renewal}

The importance of fleet renewal is justified in relation to active preference. It consists mainly in increasing the subjective sense of quality of service provided by customers. A comfortable ride in an air-conditioned, clean and pleasant-looking car is a good public image for transport companies and will certainly not dissuade the public from using other means of transport. On the contrary, it can improve the image of the public transport system and improve the quality of the services provided.

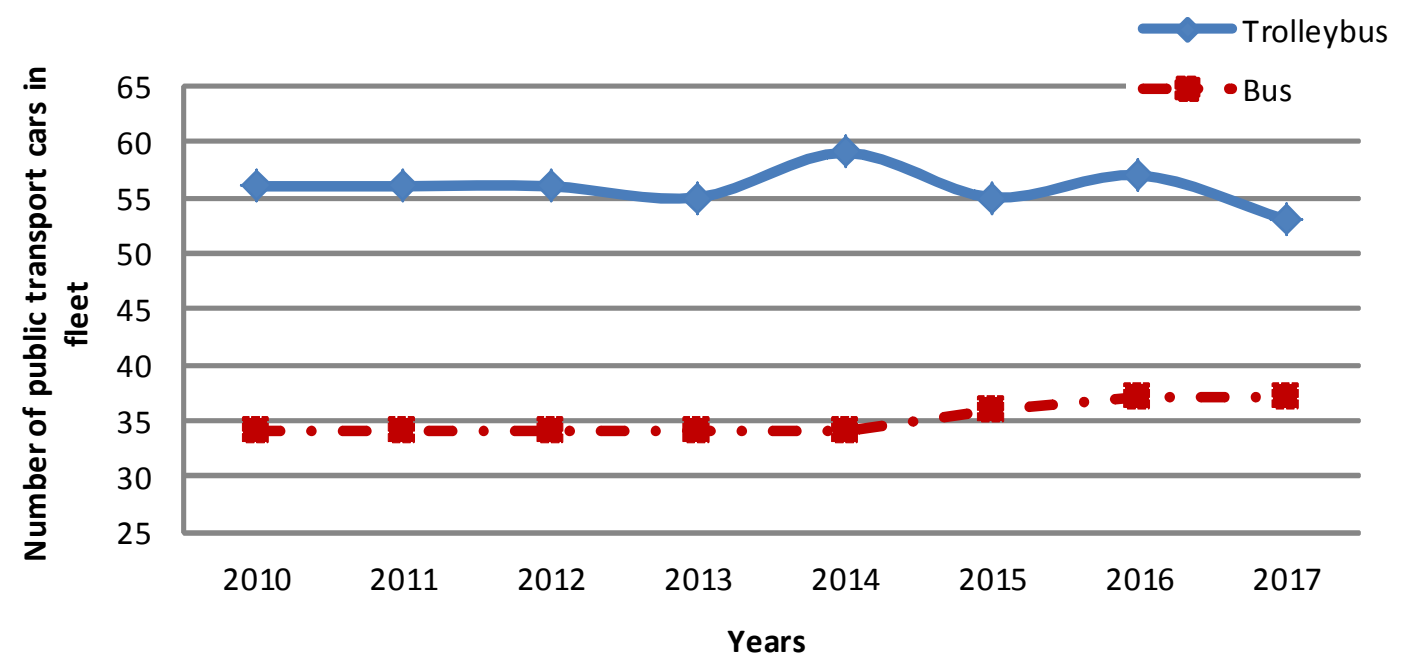

Fig. 3. Number of public transport cars in fleet in 2010-2017

Figure 3 illustrates the continuous decline and growth of individual types of public transport vehicles between 2010 and 2017. The number of trolleybuses up to a slight increase in 2014 and 2016 decreased and the total number of buses gradually increased until 2016. The number of buses in 2017 remained unchanged, as in 2016. In 2017 it had a company DSZO with 53 trolleybuses and 37 buses.

\section{Conclusions}

Based on the contribution of the presented project "Preference and Area Coordination of Public Transport" of the town's public transport company Dopravní společnost Zlín-Otrokovice in the Czech Republic, it can be stated that thanks to the built system there was a reduction of public transport times by means of effective preferential arrangements at traffic lights, increased regularity of operation and accuracy of timetables, reducing waiting times at traffic lights and reducing the energy intensity of public transport by limiting the number of repeated stops and races on the track and the related reduction of pollutant and noise emissions.

This article dealt with the possibility of saving time on the town's public transport company Dopravní společnost Zlín-Otrokovice in the Czech Republic links by introducing an active preference system. Here are the calculation methods given for obtaining relevant time saving results in seconds and in percent by comparing 2009, when active preference of urban transport vehicles was not introduced, and 2017 after the active preference was put into operation.

Based on the analysis, after the revision for 2017, the value of the time savings parameter on urban transport lines was 5,580 seconds and time savings of $8.5 \%$. It follows from the above that a measure has been introduced into the transport system in Zlín and Otrokovice, which has enabled the modification of chronometrages, which have shortened travel time on all the routes.

After the analysis we can state that the obligation to fulfil the main monitoring indicator of reducing the transit time of public transport for 2017 was established by setting up an active preference. Thanks to the active preference, the town's public transport company Dopravní společnost Zlín-Otrokovice gained more time for passengers to get in and out, less waiting for traffic lights at crossroads and faster Zlín and Otrokovice passage. At present, 38 intersections with light signaling from the total number of 39 junctions are involved in the preference and the area co-ordination of public transport in Zlín and Otrokovice. At a total distance of 384,669 meters on all 21 lines and 
90 vehicles of public transport, 5,580 seconds were saved. Another goal is to further improve public transport and make it competitive with individual transport.

\section{Acknowledgements}

This study is funded by the University of Pardubice (No. SGS_2018_023).

\section{References}

[1] Buehler R. Determinants of transport mode choice: a comparison of Germany and the USA. Journal of Transport Geography, vol. 19, 2011, pp. 644-657.

[2] Enoch F. S., Kofi Adu-Boahen, Kwaku Kissah-Korsah. Assessing the factors that in fluence public transport mode preference and patronage: Perspectives of students of University of Cape Coast (UCC), Ghana. International Journal of Development and Sustainability, vol. 3, 2014, pp. 323-336.

[3] Nutsugbodo Y. R., Amenumey K. E., Mensah A. C. Public transport mode preferences of international tourists in Ghana: Implications for transport planning. Travel Behaviour and Society, vol. 11, 2018, pp. 1-8.

[4] Svet Dopravy. Aktívna detekcia vozidiel MHD pomocou ITS. [online] [11.03.2018]. Available at: http://www.svetdopravy.sk/aktivna-detekcia-vozidiel-mhd-pomocou-its/.

[5] Mingbao Z., Hui Ch., Liqiang Y., Ying Ch. Public Transport Connecting Preference Model Based on Generalized Travel Utility. Intelligent Computation Technology and Automation, vol. 4, 2009. [online] [15.4. 2018]. Available at: https://ieeexplore.ieee.org/document/5288072/.

[6] Jacura M., Havlena O. Metodika pro vyčíslení pozitivních efektů preference VHD. Měřitelné prrínosy preference veřejné hromadné dopravy. [online] [19.4.2018]. Available at: http://preferencevhd.info/wp-content/uploads/2017/01/PREFOS-

M \%C4 \%9B \%C5 \%99iteln \%C3 \%A9-p \%C5 \%99 \%C3 \%ADnosy-preferenceve \%C5 \%99ejn \%C3 \%A9-hromadn \%C3\%A9-dopravy-FINAL.pdf.

[7] Bursík D. Preference public transport in Českých Budějovicích. Dissertation study program Transport Systems and Technology, 2017. Prague: Czech Technical University in Prague, Faculty of Transportation Engineering, 2017. [online] [19.4.2018]. Available at: https://dspace.cvut.cz/handle/10467/70430.

[8] Kupculjakova J. Model preferences of urban public transport in the city of Zilina, Dissertation thesis. [online] [01.03.2018]. Available at:

http://crzp.sk/crzpopacxe?fn=resultform\&rankfield=true \&prequelF $=\& \mathrm{fs}=$ 108B028E377C420DAE66812F24B1FA08.

[9] Good journey innovations. [online] [07.04.2018]. Available at: http://www.cross.cz/en/productstraffic-control. 